\title{
The Sign Test with Ties Included
}

\author{
Jennings B. Marshall \\ Brock School of Business, Samford University, Birmingham, USA \\ Email: jbmarsja@samford.edu
}

Received 4 April 2014; revised 4 May 2014; accepted 11 May 2014

Copyright (C) 2014 by author and Scientific Research Publishing Inc.

This work is licensed under the Creative Commons Attribution International License (CC BY). http://creativecommons.org/licenses/by/4.0/

(c) (i) Open Access

\begin{abstract}
The sign rank test is taught in virtually all introductory Statistics classes. When teaching the sign rank test the students are told to ignore the ties. Ignoring ties that support the null hypothesis is not logical. Why should valid data that support the null hypothesis be ignored? The approach taken here demonstrates a method for testing with ties included. A typical problem presentation in a text book would indicate that if you had ten ties in a sample of size fifty the tie scores would be excluded. However, the ten tie scores are a very valuable piece of statistical information which should not be ignored. The method demonstrated here shows that a different conclusion is reached in some cases when the ties are not excluded. Further many sign tests often will have ties because in some cases the data are not a cardinal number, but an ordinal number chosen from a set often results in ties. The alternative approach uses a one-tailed distribution and considers both +'s and -'s separated. A two-tailed test for equal variances is done with a one-tail of an F distribution. This alternate approach to the sign test allows the use of important statistical information which has been ignored with the traditional sign rank test.
\end{abstract}

\section{Keywords}

Sign Test, Ties

\section{Introduction}

The sign rank test is taught in virtually all introductory Statistics classes. When teaching the sign rank test the students are told to ignore the ties as found in six different textbooks [1]-[6].

When performing the sign rank test for equal means ties are ignored because ties produce a difference of zero, a difference of zero cannot be assigned a plus or a minus sign therefore they are ignored. The ties come from valid data which fully support the null hypothesis; there is no good justification for ignoring valid data which support the null hypothesis. When doing a one-tailed sign rank test, ties are included because the one-tailed test only requires determining what proportion of the differences have, either a positive sign or a negative sign; differences 
of zero are not part of the tail that generates the reject range so they are not excluded. Because one-tailed tests allow the utilization of ties, a modification of this process can be used to test for equal means. By simultaneously using a one-tailed test for the proportion of positive differences that is greater than or equal to $50 \%\left(\mathrm{H}_{0}\right.$ : + 's $\geq$ 0.50 ) and simultaneously using a one-tailed test for the proportion of negative differences that is greater than or equal to $50 \%\left(\mathrm{H}_{0}:-\right.$ 's $\left.\geq 0.50\right)$, the test can effectively test that of no difference. If one fails to reject $\mathrm{H}_{0}:+$ 's $\geq 0.50$ and fails to reject $\mathrm{H}_{0}$ : -'s $\geq 0.50$ one have failed to reject that $\mathrm{H}_{0}$ : Median for $\mathrm{A}-$ Median for $\mathrm{B}=0$, therefore if one fails to reject both null hypothesizes then the only possibility for both to hold true this that one cannot reject the hypothesis for $\mathrm{A}=\mathrm{B}$. The simultaneous utilization of the one tail distribution allows one to test for equal means with the inclusion of ties. Below is an example of the effect of including ties in a hypothetical problem.

\section{Example}

A typical illustration of the sign rank test would be as follows: The sign test is illustrated in terms of data obtained from a panel of sixty consumers. Let us assume a blind fold test in which the tasters are asked to rate the two cola drinks on a scale of 1 - 5 with one representing the best taste (excellent) and five representing the worst taste (poor) and other scores denoting the appropriate intermediaries. Table one shows a partial listing of the scores assigned by the panel members in this test.

Column four shows the signs of the differences between the scores assigned by each participant in columns (2) and (3). As indicated, a plus sign means a higher numerical score was assigned to cola A, a minus sign means a lower score was assigned to cola B and a zero denotes a tie score. Let us assume the following results were obtained. Plus signs 35 , minus signs 15 , zero scores 10 . By means of the sign test we can test the hypothesis of no difference in ranking of the two brands of colas or we can test the hypothesis that Brand A is preferred to B or brand B is preferred to Brand A. More specifically we can test the hypothesis that the plus and minus signs are equally likely for the differences in rankings when testing a two tailed hypothesis. If this null hypothesis were true we would expect an equal number of plus and minus signs. We would reject the null hypothesis if too many of one type of sign occurred. If we used P to denote the probability of obtaining a plus sign we can indicate the hypothesis as follows:

$$
\mathrm{H}_{0}: \mathrm{P}=0.50
$$

$\mathrm{H}_{1}: \mathrm{P} \neq 0.50$

Alternatively one could test the hypothesis that Brand A is preferred over Brand B by testing the hypothesis that the proportion of +'s are less than or exported to 0.50 .

$\mathrm{H}_{0}: \mathrm{P} \leq 0.50$ (Brand A equal or inferior to $\mathrm{B}$ )

$\mathrm{H}_{1}: \mathrm{P}>0.50$ (Brand A better than $\mathrm{B}$ )

Since ties are excluded in a sign test the data used for the test consists of thirty-five plus signs and fifteen minus signs. This problem is conceptually the same as one in which a coin has been tossed fifty times yielding thirty-five heads and fifteen tails and we wish to test the hypothesis that the coin is fair. The binomial distribution is the theoretically correct distribution. However, we can use a large sample method consisting of a normal curve approximation to the binomial.

This very typical presentation indicates that you treat this as a sample of size fifty excluding the ten tie scores. However, the ten tie scores is a very valuable piece of statistical information which should not be ignored. Further many sign tests often will have ties because the data are often not a cardinal number, but an ordinal number chosen from a very small set which often results in ties. An alternative approach when doing a one tailed test would be to include the ties. Testing the hypothesis that the proportion is $\mathrm{H}_{0}=\mathrm{P} \leq 0.50$. One would use the plus signs and treat it as a sample size sixty from which thirty-five plus signs were obtained. This way you are not deleting the valuable piece of information that is ten of the sixty people didn't think that there was any difference. Test with $\alpha=0.05$.

Ties Excluded

$\mathrm{H}_{0}=\mathrm{P} \leq 0.50+35$

$\mathrm{H}_{1}=\mathrm{P}>0.50-15$

ties 10

$$
\begin{aligned}
& n=60-10=50 \\
& +p=\frac{35}{50}=0.70
\end{aligned}
$$




$$
Z=\frac{(0.7-0.5)}{\sqrt{0.5(1-0.5)\left(\frac{1}{50}\right)}}=2.82 b
$$

Reject $\mathrm{H}_{0}$ if $\mathrm{Z}>+1.65$

Reject $\mathrm{H}_{0}$ if $\mathrm{Z}>+1.96$ or if $\mathrm{Z}<-1.96$

Otherwise, do not reject $\mathrm{H}_{0}$

Therefore, reject $\mathrm{H}_{0}$

Alternative with ties

$\mathrm{H}_{0}=\mathrm{P} \leq 0.50$

$\mathrm{H}_{1}=\mathrm{P}>0.50$

$n=60$

$$
\begin{gathered}
+\mathrm{p}=\frac{35}{60}=0.583 \\
\mathrm{Z}=\frac{(0.583-0.5)}{\sqrt{0.5(1-0.5)\left(\frac{1}{60}\right)}}=1.288
\end{gathered}
$$

Reject $\mathrm{H}_{0}$ if $\mathrm{Z}>+1.65$

Otherwise, do not reject $\mathrm{H}_{0}$

Therefore, do not reject $\mathrm{H}_{0}$

One would not expect to get 35+ sign out of sample of size $50(Z=2.82)$. However, this result was obtained because we ignored 10 ties. When the ties are included the proportion that prefers Brand A drops to 0.583 (35/50). This is clearly not enough to cause one to conclude that cola $A$ is preferred $(Z=1.28)$. This example with 10 ties in a sample of size 60 was taken from a current text book and is typical. Some books will not note when a large number of ties occur the sign is not appropriate. However, none view 10 out of 60 are a large number of ties.

Now consider a sign test that uses a small sample that actually applies the binomial probability distribution rather than the approximation. This example will only have two ties in a sample of size 20. Suppose 20 people were surveyed about the product and you had two ties and 12 that thought the product was better and 6 that thought it was worse. Excluding ties you would now have 12 plus signs with an $\mathrm{N}$ of 18 . Using the binomial probability distribution table the cumulative probability of getting 12 or more is 0.048 . One would therefore reject the null hypothesis and conclude that there was a significant difference. However, if you did not ignore the two ties you would find only 12 out of 20 that thought the product was better and the 12 out of 20 would be at a $\mathrm{P}$ value of 0.132 one clearly would not reject a hypothesis with a critical value of 0.132 so ignoring a valuable piece of information I would contend would lead to an incorrect decision. This demonstrates the effect of just 2 tries.

\section{Alternative Approach}

Two tailed sign test have ignored the tries because of the desire to have a symmetrical distribution. An alternative approach would be to use a one tailed distribution and considering both +'s and -'s separated. A two tailed test for equal variances is done with one tail of an F distribution. Likewise, one tail of a standard normal distribution can be used with this approach.

$\mathrm{H}_{0}=\mathrm{P}<0.50$ (preference for $\mathrm{A}$ is less than or equal to 0.50 and then preference for $\mathrm{B}$ is less than or equal to 0.50 if you accept both the conclusion is preference is equal)

$\mathrm{H}_{1}=\mathrm{P}>0.50$ +'s and -'s

Test to see if you have enough +'s to reject the null hypothesis, then check to see if the proportion of -'s is enough to reject the null hypothesis. If you cannot reject the null hypothesis with either the +'s or the -'s then there is not enough evidence to conclude there is a difference. If then you reject the null hypothesis with either the +'s or the -'s then the null hypothesis is reject.

The cola brand preference problem can be used to illustrate the test.

$\mathrm{H}_{0}: \mathrm{P} \leq 0.50$ test with $\alpha=0.05$ 
$\mathrm{H}_{1}: \mathrm{P}>0.50$

Reject $\mathrm{H}_{0}$ if $\mathrm{Z}_{0}>+1.96$

Otherwise, do not reject $\mathrm{H}_{0}$

Since the null hypothesis can be rejected by the +'s or the -'s when testing at the 0.05 level the critical value is defined by the $\mathrm{Z}$ value that separates 0.025 .

first +'s

$$
\begin{gathered}
+\mathrm{p}=\frac{35}{60}=0.583 \\
\mathrm{Z}=\frac{(0.583-0.5)}{\sqrt{0.5(1-0.5)\left(\frac{1}{60}\right)}}=1.288
\end{gathered}
$$

Therefore, do not reject $\mathrm{H}_{0}$

now -'s

$$
\begin{gathered}
-\mathrm{p}=\frac{15}{60}=0.25 \\
\mathrm{Z}=\frac{(0.25-0.5)}{\sqrt{0.5(1-0.5)\left(\frac{1}{60}\right)}}=-3.846
\end{gathered}
$$

Reject $\mathrm{H}_{0}$ if $\mathrm{Z}>+1.96$

Otherwise, do not reject $\mathrm{H}_{0}$

Therefore, do not reject $\mathrm{H}_{0}$

To summarize only 15 out of 60 preferred Brand B so there is no reason to conclude that cola B is preferred to Cola A. But is A preferred to B? 35 out of 60 preferred A to B but that is only a little over half $(\mathrm{Z}=1.288)$ and is not sufficient to conclude that $A$ is preferred to $B$. If $B$ is not preferred to A and A is not preferred to $B$ then we cannot reject the null hypothesis that preference for $\mathrm{A}$ is equal to preference for $\mathrm{B}$.

\section{Conclusions}

As demonstrated earlier when doing the one-tail test with the 10 ties dropped $Z=2.82$. Therefore, the traditional two-tailed test for $\mathrm{A}=\mathrm{B}$ would have rejected the null hypothesis that only the decision rule would change and $\mathrm{Z}$ $=2.82$ would be in the reject range at the 0.05 level.

This alternate approach to the sign test allows the use of important statistical information which has been ignored with the traditional test.

\section{References}

[1] Anderson, D.R., Sweeney, D.J., Williams, T.A., et al. (2014) Statistics for Business and Economics. 12th Edition, West Publishing Company, Minneapolis/St. Paul, 880-883.

[2] Berenson, M.L., Levine, D.M. and Krehbiel, T.C. (2013) Basic Business Statistics. 13th Edition, Pearson Prentice Hall, Upper Saddle River, 534-538.

[3] Black, K. (2012) Business Statistics for Contemporary Decision Making. 7th Edition, John Wiley \& Sons, Hoboken, 700-703.

[4] Groebner, D.F., Shannon, P.W. and Fry, P.C. (2014) Business Statistics: A Decision-Making Approach. 9th Edition, Pearson Prentice Hall, Upper Saddle River, 754-757.

[5] Jaggia, S. and Kelly, A. (2013) Business Statistics, Communicating with Numbers. McGraw-Hill, Irwin, 631-633.

[6] Newbold, P., Carlslon, W. and Thorne, B. (2013) Statistics for Business and Economics. 8th Edition, Pearson Prentice Hall, Upper Saddle River, 599-604. 